\title{
Population pharmacokinetics model and initial dose optimization of tacrolimus in children and adolescents with lupus nephritis based on real-world data
}

\author{
$\mathrm{XIAO} \mathrm{CHEN}^{1 *}$, DONG-DONG WANG ${ }^{1 *}, \mathrm{HONG} \mathrm{XU}^{2}$ and ZHI-PING LI ${ }^{1}$ \\ Departments of ${ }^{1}$ Pharmacy and ${ }^{2}$ Nephrology, Children's Hospital of Fudan University, Shanghai 201102, P.R. China
}

Received January 28, 2020; Accepted May 1, 2020

DOI: $10.3892 /$ etm.2020.8821

\begin{abstract}
The present study aimed to establish a population pharmacokinetics model of tacrolimus and further optimize the initial dosing regimen of tacrolimus in pediatric and adolescent patients with lupus nephritis (LN). Pediatric and adolescent patients with LN were recruited between August 2014 and September 2019 at the Children's Hospital of Fudan University (Shanghai, China). Relevant information was used to set up a population pharmacokinetics model with a Nonlinear Mixed Effect Model and the initial dosage regimen was simulated with the Monte Carlo method. Body weight and co-administration of wuzhi capsule were indicated to influence tacrolimus clearance in pediatric and adolescent patients with LN, and at the same body weight, the rate of tacrolimus clearance in patients without vs. with co-administration of wuzhi capsule was 1:0.71. In addition, in patients who were not administered wuzhi capsule, an initial dosage regimen of $0.15 \mathrm{mg} / \mathrm{kg} / \mathrm{day}$ was recommended for a body weight of $10-23 \mathrm{~kg}$ and $0.10 \mathrm{mg} / \mathrm{kg} / \mathrm{day}$ for $23-60 \mathrm{~kg}$; in patients who were administered wuzhi capsule, an initial dosage regimen of $0.10 \mathrm{mg} / \mathrm{kg} /$ day was recommended for a body weight of $10-23 \mathrm{~kg}$ and $0.05 \mathrm{mg} / \mathrm{kg} / \mathrm{day}$ for $23-60 \mathrm{~kg}$. To the best of
\end{abstract}

Correspondence to: Professor Hong $\mathrm{Xu}$, Department of Nephrology, Children's Hospital of Fudan University, 399 Wanyuan Road, Shanghai 201102, P.R. China

E-mail: hxu@shmu.edu.cn

Professor Zhi-Ping Li, Department of Pharmacy, Children's Hospital of Fudan University, 399 Wanyuan Road, Shanghai 201102, P.R. China

E-mail: zpli@fudan.edu.cn

${ }^{*}$ Contributed equally

Abbreviations: CL/F, apparent oral clearance; CYP3A, cytochrome $\mathrm{P} 450$, family 3; Ka, absorption rate constant; LN, lupus nephritis; OFV, objective function values; SLE, systemic lupus erythematosus; $\mathrm{V} / \mathrm{F}$, volume of distribution; VPC, prediction-corrected visual predictive check; WRES, weighted residuals

Key words: population pharmacokinetics, initial dose optimization, tacrolimus, children and adolescents, lupus nephritis our knowledge, the present study was the first to establish a population pharmacokinetics model of tacrolimus in order to determine the optimal initial dosage regimen of tacrolimus in pediatric and adolescent patients with $\mathrm{LN}$.

\section{Introduction}

Systemic lupus erythematosus (SLE) is a multisystemic autoimmune disease (1) characterized by connective-tissue inflammation and extensive vasculitis (2-5). It primarily occurs in adolescents aged 10-19 years, although 1/3 of affected patients are $<10$ years old and the majority are females $(1,6)$. Organ lesions in pediatric and adolescent patients with SLE are more severe than those in adults and may lead to death in a relatively short time, being associated with dismal prognoses (1). Pediatric and adolescent patients with SLE frequently have complex and severe clinical manifestations $(1,6)$ that affect various different organs, either simultaneously or successively involving multiple systems, including the urinary, nervous, cardiovascular and blood supply systems (1).

Lupus nephritis (LN) is one of the most severe complications of SLE and its incidence rate reaches up to $60 \%$ in patients with SLE worldwide. Among patients with SLE, $50-80 \%$ are cases of pediatric-onset SLE (7-10). As comprehensively reviewed (10), without pharmacotherapy, long-term LN may induce irreversible renal injury and subsequently develops into end-stage renal disease. Traditional treatments of LN involve a combination therapy of cyclophosphamide with glucocorticoids, which have been demonstrated to improve the long-term prognosis. However, its usage is limited by severe adverse effects, including hemorrhagic cystitis, amenorrhea, malignancy and sepsis. Novel immunosuppressants, including tacrolimus, cyclosporine and mycophenolate mofetil are required to inhibit the side effects of traditional treatments. Tacrolimus has been reported to be a safe and effective agent for treating patients with LN (10).

However, considerable intra- and inter-individual pharmacokinetic variability makes it difficult to establish individualized tacrolimus dosage regimens. Of note, population pharmacokinetics is able to differentiate in terms of pharmacokinetic variability and has a higher statistical power to verify the effect of multiple factors on the pharmacokinetic behaviour of tacrolimus compared to traditional pharmacokinetic analysis and makes it possible to formulate an optimal 
dosage schedule $(11,12)$. Hence, the present study aimed to establish a population pharmacokinetics model of tacrolimus and further optimize the initial dosage regimen for tacrolimus in pediatric and adolescent patients with $\mathrm{LN}$.

\section{Patients and methods}

Study design. The clinical information of pediatric and adolescent patients with LN treated between August 2014 and September 2019 at the Children's Hospital of Fudan University (Shanghai, China) was retrospectively collected. The clinical information was collected from the hospital's information system and tacrolimus whole-blood levels were acquired from a therapeutic drug detection system. Partial basic clinical information data with partial overlap were collected from certain patients in previous studies $(13,14)$. The present study was approved by the Research Ethics Committee of the Children's Hospital of Fudan University [ethical approval code: (2019)020]. The present study was a retrospective study and was approved by the ethics committee of this hospital without the requirement for written informed consent. A previous study have used lower patient numbers (15).

Population pharmacokinetics modeling. The population pharmacokinetics model was established using Nonlinear Mixed Effects Modeling software (NONMEM ${ }^{\circledR}$; version VII; ICON Development Solutions Ltd.) by the first-order conditional estimation method with interaction. The pharmacokinetics parameters included apparent oral clearance (CL/F), volume of distribution $(\mathrm{V} / \mathrm{F})$ and absorption rate constant $(\mathrm{Ka})$, where the value of Ka was fixed at 4.48 per hour (13,16-18). Inter-individual variabilities were estimated by equation (i): $\mathrm{A}=\mathrm{T}(\mathrm{A}) \times \exp \left(\eta_{\mathrm{i}}\right)$. A and $\mathrm{T}(\mathrm{A})$ represent the individual parameter value and the typical individual parameter value, respectively. $\eta_{\mathrm{i}}$ represented a symmetrical distribution $\left(0, \omega^{2}\right)$, which was a random term with zero mean and variance $\omega$ squared $\left(\omega^{2}\right)$.

Random residual variabilities were estimated by equation (ii): $A=\left(1+\varepsilon_{1}\right) \times B$. $A$ and $B$ represent the observed concentration and the individual predicted concentration, respectively. $\varepsilon_{1}$ represented a symmetrical distribution $\left(0, \sigma^{2}\right)$, which was a random term with zero mean and variance $\sigma$ squared $\left(\sigma^{2}\right)$.

Covariate model. Weight and pharmacokinetics parameters were estimated by equation (iii): $\mathrm{A}_{\mathrm{i}}=\mathrm{A}_{\text {std }} \mathrm{x}\left(\mathrm{WT}_{\mathrm{i}} / \mathrm{WT}_{\mathrm{std}}\right)^{\text {power }}$. $\mathrm{A}_{\mathrm{i}}$ and $\mathrm{WT}_{\mathrm{i}}$ represent the $\mathrm{i}$-th individual pharmacokinetics parameter and the $\mathrm{i}$-th individual body weight, respectively. $\mathrm{A}_{\text {std }}$ represents the typical individual parameter of $\mathrm{WT}_{\text {std }}\left(\mathrm{WT}_{\text {std }}\right.$ was the standard body weight, which was $70 \mathrm{~kg}$ ). Power was the allometric coefficient, which was set at 0.75 for the CL/F and 1 for the V/F (19). Continuous covariates and categorical covariates were estimated by equation (iv) and (v), respectively: $\mathrm{A}_{\mathrm{i}}=\mathrm{T}(\mathrm{A}) \times\left(\operatorname{Cov}_{\mathrm{i}} / \operatorname{Cov}_{\text {median }}\right)^{\theta}$ and $\mathrm{A}_{\mathrm{i}}=\mathrm{T}(\mathrm{A}) \times\left(1+\operatorname{Cov}_{\mathrm{i}} \times \theta\right) . \mathrm{A}_{\mathrm{i}}$ and $\mathrm{T}(\mathrm{A})$ represent the individual parameter value and the typical individual parameter value, respectively. $\theta$ represents the parameter to be estimated and $\operatorname{Cov}_{\text {median }}$ is the population median for the covariate. $\operatorname{Cov}_{\mathrm{i}}$ represents the covariate of the $\mathrm{i}$-th individual. When a covariate was finally incorporated into the model, the corresponding $\theta$ value was obtained.
Changes in objective function values (OFV) were assessed by covariate inclusions and a decrease of OFV $>3.84(\mathrm{P}<0.05)$. An increase in OFV >6.63 $(\mathrm{P}<0.01)$ was considered sufficient for significance in the final model.

Evaluation and simulation. The reliability and stability of the final parameters were assessed by bootstrap $(n=1,000)$, which was performed using the NONMEM ${ }^{\circledR}$ software (version VII; ICON Development Solutions Ltd), goodness of fit plots and prediction-corrected visual predictive check (VPC) plots. The Monte Carlo method was used for the simulation of the optimal initial dose, including six weight groups $(10,20,30,40,50$ and $60 \mathrm{~kg})$ and seven initial dosing regimens $(0.01,0.05,0.10,0.15$, $0.20,0.25$ and $0.30 \mathrm{mg} / \mathrm{kg}$ daily) split into two doses. Based on previous publications, the therapeutic window of tacrolimus treatment in $\mathrm{LN}$ is between 5 and $15 \mathrm{ng} / \mathrm{ml}$; thus, this was used in the present study (10).

\section{Results}

Data collection. The clinical information of 32 pediatric and adolescent patients with LN (5 males and 27 females) was collected for the present study and was used for population modelling. The clinical information of certain patients was collected in previous studies $(13,14)$. Table I presents patient characteristics and drug combinations.

Population pharmacokinetic model. The final covariate model was described by equations (vi) and (vii), respectively: $\mathrm{CL} / \mathrm{F}=\theta_{\mathrm{CL} / \mathrm{F}} \times(\mathrm{WT} / 70)^{0.75} \times\left(1+\mathrm{WZ} \times \theta_{\mathrm{WZ}}\right)$ and $\mathrm{V} / \mathrm{F}=\theta_{\mathrm{V} / \mathrm{F}} \times$ (WT/70). $\theta_{\mathrm{CL} / \mathrm{F}}$ and $\theta_{\mathrm{V} / \mathrm{F}}$ are the typical population values of $\mathrm{CL} / \mathrm{F}$ and $\mathrm{V} / \mathrm{F}$, respectively. $\theta_{\mathrm{WZ}}$ is the coefficient of wuzhi capsule. When patients were co-administered wuzhi capsule and tacrolimus, $\mathrm{WZ}=1$ was used; otherwise, $\mathrm{WZ}=0$ was applied.

Validation. As presented in Fig. 1, observations vs. population predictions, observations vs. individual predictions, conditional weighted residuals (WRES) vs. population predictions and conditional WRES vs. time after the start of therapy were assessed in goodness of fit plots. The parameter estimates of the final model and bootstrap validation are presented in Table II. The prediction-corrected visual predictive check plots of the final model are provided in Fig. 2, where most of the observations are within the $95 \%$ prediction intervals of the simulation data, indicating that the prediction-corrected concentrations were well predicted by the final model.

Simulation. Body weight and co-administration of wuzhi capsule affected tacrolimus clearance in pediatric and adolescent patients with $\mathrm{LN}$, and for the same body weight, the rate of tacrolimus clearance in patients who were not administered wuzhi capsule vs. those who were administered wuzhi capsule was 1:0.71 (Fig. 3). Fig. 4 presents the probability of achieving the target concentrations under different initial doses. In addition, in patients who were not administered wuzhi capsule, the initial dosage regimen of $0.15 \mathrm{mg} / \mathrm{kg} / \mathrm{day}$ was recommended for a body weight of $10-23 \mathrm{~kg}$ and $0.10 \mathrm{mg} / \mathrm{kg} / \mathrm{day}$ for $23-60 \mathrm{~kg}$; in patients who were co-administered wuzhi capsule and tacrolimus, the initial dosage regimen of $0.10 \mathrm{mg} / \mathrm{kg} /$ day was 
Table I. Demographic data of patients $(n=32)$ and drug combinations.

\begin{tabular}{lcc}
\hline Characteristic & N or mean \pm SD & Median (range) \\
\hline Gender (male/female) & $5 / 27$ & $13.87(2.86-17.99)$ \\
Age (years) & $13.44 \pm 2.86$ & $47.00(17.00-66.50)$ \\
Body weight $(\mathrm{kg})$ & $45.89 \pm 10.55$ & $39.40(10.00-49.30)$ \\
Albumin $(\mathrm{g} / \mathrm{l})$ & $38.24 \pm 6.21$ & $10.00(1.00-123.00)$ \\
Alanine transaminase (IU/l) & $13.88 \pm 15.69$ & $15.00(5.00-79.80)$ \\
Aspartate transaminase (IU/l) & $16.37 \pm 8.10$ & $54.00(16.00-225.00)$ \\
Creatinine $(\mu$ mol/l) & $55.71 \pm 19.59$ & $5.80(2.10-27.30)$ \\
Urea (mmol/l) & $6.14 \pm 2.61$ & $65.20(37.90-79.70)$ \\
Total protein $(\mathrm{g} / \mathrm{l})$ & $64.26 \pm 7.13$ & $3.70(0.90-85.50)$ \\
Total bile acid $(\mu$ mol/l) & $4.78 \pm 6.34$ & $1.40(0.20-55.10)$ \\
Direct bilirubin $(\mu$ mol/l) & $1.68 \pm 3.56$ & $6.00(2.30-64.90)$ \\
Total bilibrubin $(\mu$ mol/l) & $6.34 \pm 4.12$ & $36.50(20.50-50.00)$ \\
Hematocrit $(\%)$ & $36.57 \pm 4.85$ & $120.00(70.20-290.00)$ \\
Hemoglobin $(\mathrm{g} / \mathrm{l})$ & $122.01 \pm 21.97$ & $28.00(21.00-35.00)$ \\
Mean corpuscular hemoglobin $(\mathrm{pg})$ & $28.15 \pm 2.33$ & $333.00(271.00-383.00)$ \\
Mean corpuscular hemoglobin concentration $(\mathrm{g} / \mathrm{l})$ & $330.25 \pm 13.93$ & \\
Co-medication & & 32 \\
Glucocorticoid & & 12 \\
Wuzhi capsule & &
\end{tabular}

$\mathrm{SD}$, standard deviation.
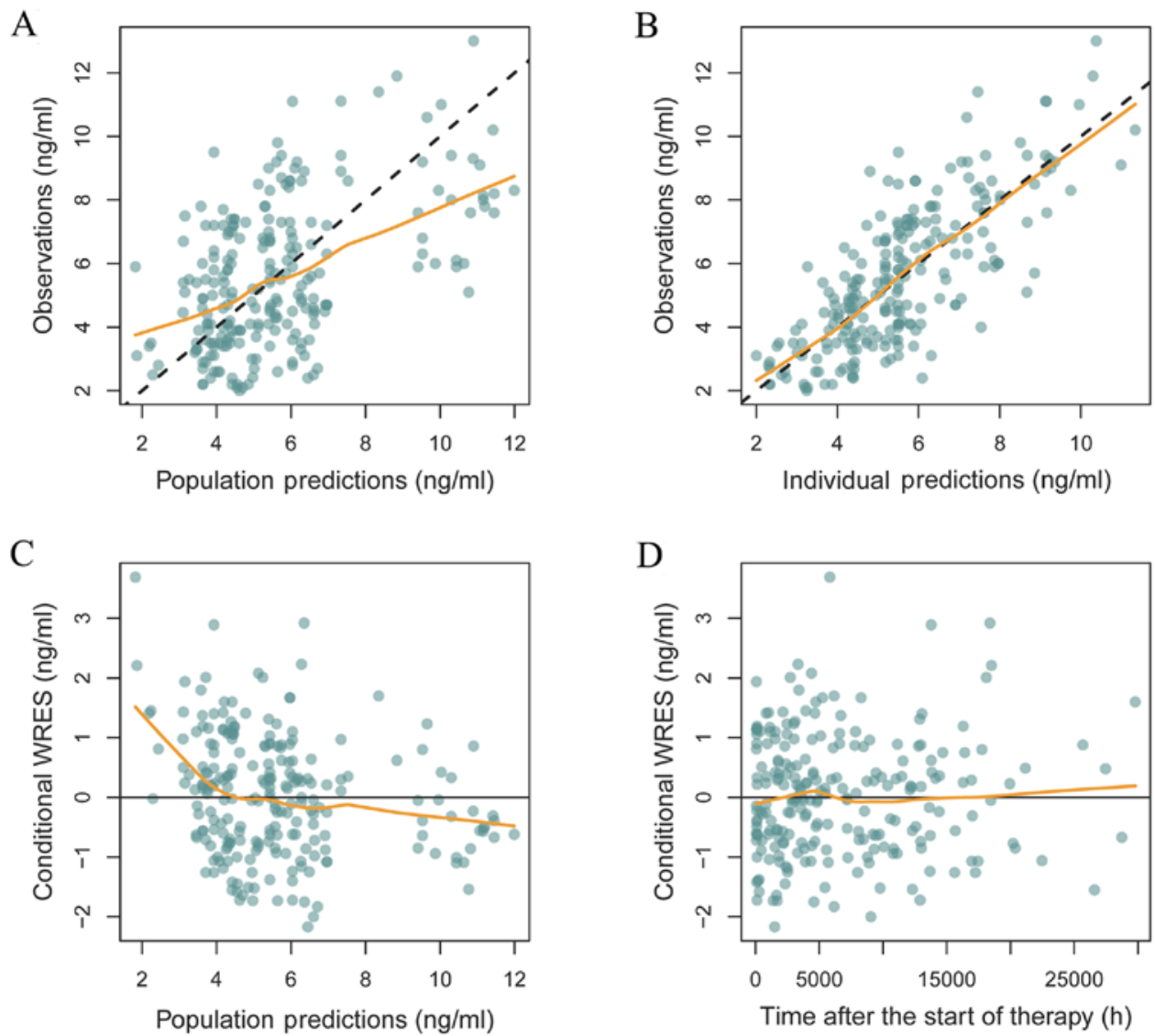

Figure 1. The final model goodness-of-fit plots. (A) Observations vs. population predictions. (B) observations vs. individual predictions, (C) conditional WRES vs. population predictions and (D) conditional WRES vs. time after the start of therapy. WRES, weighted residuals. Partial concentration values were collected based on previous studies $(13,14)$. 
Table II. Parameter estimates of the final model and bootstrap validation.

\begin{tabular}{lccccc}
\hline & & & \multicolumn{2}{c}{ Bootstrap } \\
\cline { 4 - 6 } Parameter & Estimate & SE & Median & $95 \%$ CI & Bias \\
\hline $\mathrm{CL} / \mathrm{F}(1 / \mathrm{h})$ & 15.5 & 0.729 & 18.5 & {$[2.5,24.4]$} & 0.194 \\
$\mathrm{~V} / \mathrm{F}(\mathrm{l})$ & 174 & 1.908 & 303 & {$[8,1200]$} & 0.741 \\
$\mathrm{Ka}(1 / \mathrm{h})$ & $4.48($ fixed $)$ & - & - & - & - \\
$\theta_{\mathrm{WZ}}$ & -0.290 & 0.390 & -0.297 & {$[-0.440,-0.133]$} & 0.024 \\
$\omega_{\mathrm{CL} / \mathrm{F}}$ & 0.172 & 0.461 & 0.175 & {$[0.073,0.292]$} & 0.017 \\
$\sigma_{1}$ & 0.281 & 0.049 & 0.277 & {$[0.249,0.305]$} & -0.014 \\
\hline
\end{tabular}

The $95 \%$ CI was displayed as the 2.5th, 97.5th percentile of bootstrap estimates. CL/F, apparent oral clearance; V/F, apparent volume of distribution; Ka, absorption rate constant; $\theta_{\mathrm{WZ}}$, coefficient of wuzhi capsule; $\omega_{\mathrm{CL} / \mathrm{F}}$, inter-individual variability of CL/F; $\sigma_{1}$, residual variability, proportional error; SE, standard error; Bias, prediction error [Bias=(Median-Estimate)/Estimate].

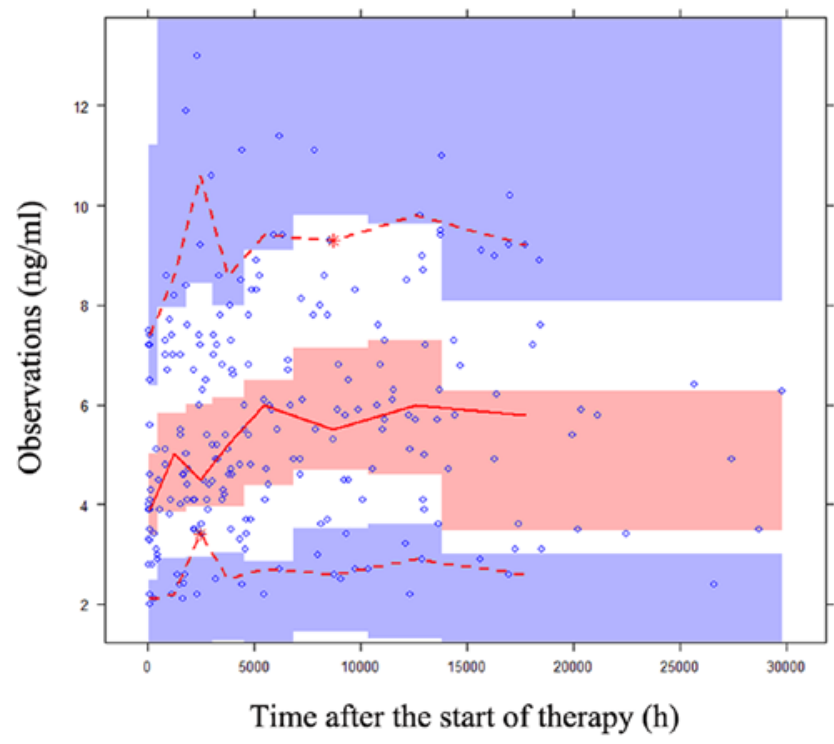

Figure 2. The final model VPC plots. The y-axis represents the observed whole blood concentration of tacrolimus. The middle solid line represents the median of the prediction-corrected concentrations. The lower and upper dashed lines are the 2.5th and 97.5th percentiles of the prediction-corrected concentrations, respectively. The blue points represents observed concentrations (measured concentrations). The pink zone represents the confidence interval of the middle solid line and the purple zones indicate the confidence interval of the lower and upper dashed lines. VPC, prediction-corrected visual predictive check. Partial concentration values were collected based on previous studies $(13,14)$.

recommended for a body weight of $10-23 \mathrm{~kg}$ and $0.05 \mathrm{mg} / \mathrm{kg} /$ day for 23-60 kg, as presented in Table III.

\section{Discussion}

Tacrolimus, also known as FK506, is a 23-membered lactone ring that is isolated from Streptomyces tsukubaensis and used as a potent immunosuppressant. It has been reported that tacrolimus is 100 times stronger than cyclosporine and it may exert its effects by inhibiting the function of $\mathrm{T}$ lymphocytes and downregulating the expression of interleukin-2 $(20,21)$. In addition, it has been used as the first-line drug for patients

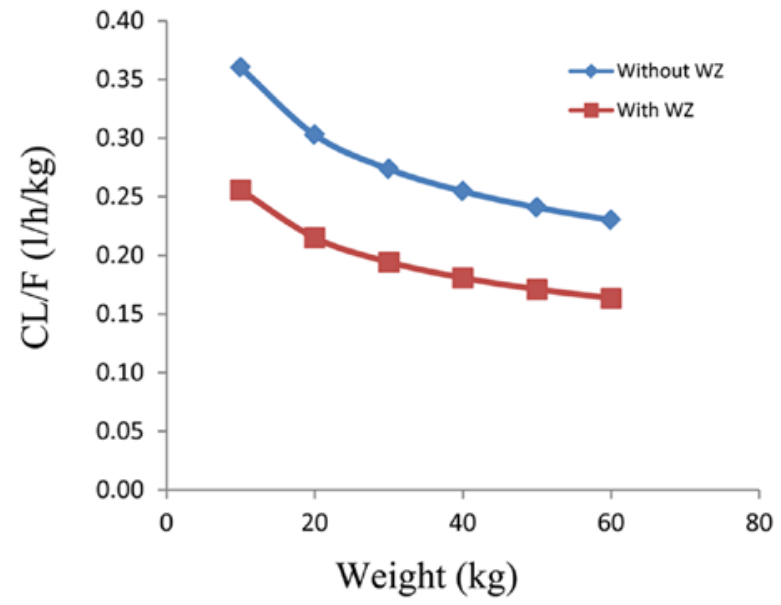

Figure 3. CL/F of tacrolimus in children and adolescents with lupus nephritis. WZ, wuzhi capsule; CL/F, apparent oral clearance.

with liver and renal transplant (16,22-34). Furthermore, it has been demonstrated that tacrolimus may be used to improve the outcome of patients who undergo bone marrow (35-42), lung (43) and heart transplantation (44).

In previous years, clinical experiments have also indicated that tacrolimus has useful applications in systemic-onset juvenile idiopathic arthritis (45-48), nephrotic syndrome (49-55), SLE (56-65), myasthenia gravis $(66,67)$, ulcerative colitis $(68,69)$ and autoimmune hepatitis $(70)$. Furthermore, according to a previous review article, tacrolimus is a safe and effective agent for treating patients with LN (10).

It has been reported that the underlying mechanism of action of tacrolimus in LN is primarily its inhibitory effect on the dephosphorylation of the nuclear factor of activated T cells, which thereby reduces the activity of genes encoding interleukin-2 and associated cytokines (71), leading to the inhibition of T-cell activation. In addition, the effect of tacrolimus on $\mathrm{LN}$ is also the result of its well-known antiproteinuric effects that have been utilized in the treatment of a variety of kidney pathologies (72). It has also been reported that in mouse models of SLE, tacrolimus inhibits the progression of glomerular hypercellularity, crescent formation and proteinuria development, 

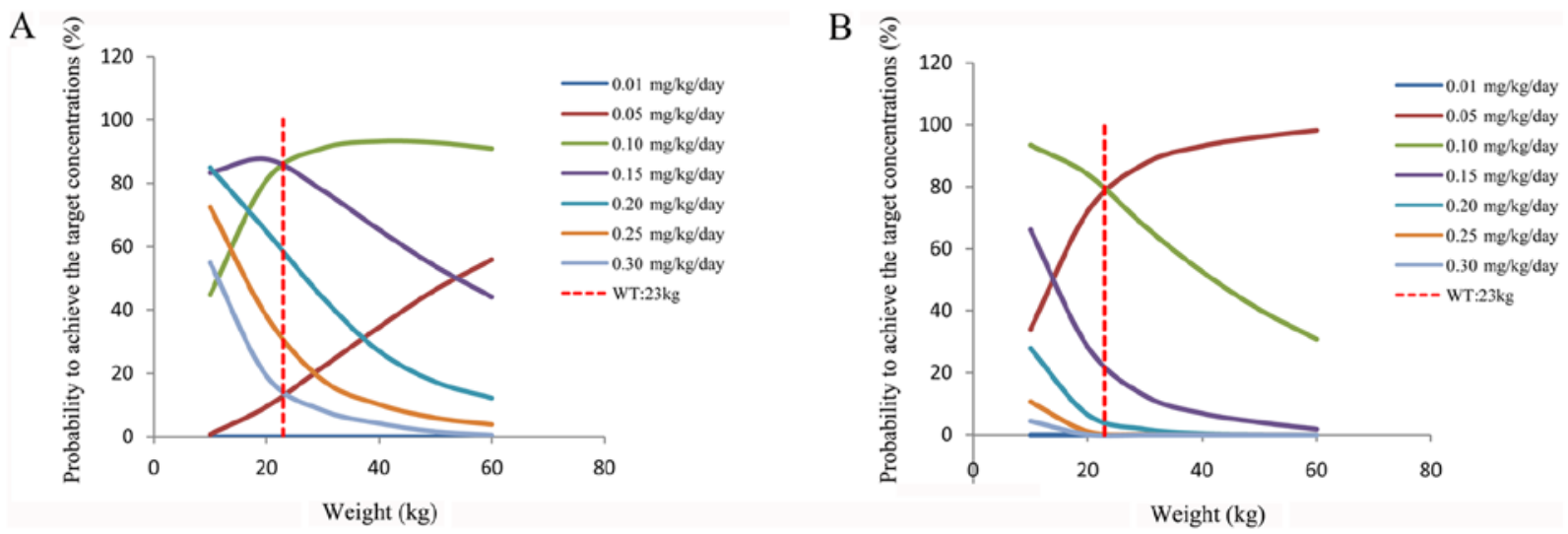

Figure 4. Probability to achieve the target concentrations (A) in patients without administration of wuzhi capsule and (B) in patients with administration of wuzhi capsule. WT, individual body weight.

Table III. Initial dose recommendations of tacrolimus in children and adolescents with lupus nephritis.

\begin{tabular}{lcc}
\hline $\begin{array}{l}\text { Drug combination } \\
\text { with wuzhi capsule }\end{array}$ & $\begin{array}{c}\text { Body } \\
\text { weight }(\mathrm{kg})\end{array}$ & $\begin{array}{r}\text { Dose recommendation } \\
(\mathrm{mg} / \mathrm{kg} / \mathrm{day})^{\mathrm{a}}\end{array}$ \\
\hline No & $10-23$ & 0.15 \\
No & $23-60$ & 0.10 \\
Yes & $10-23$ & 0.10 \\
Yes & $23-60$ & 0.05 \\
\hline
\end{tabular}

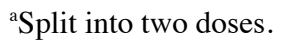

and suppresses the increase of anti-double-stranded DNA antibody serum levels in animal models of spontaneous LN (73). Therefore, from the above perspective, the mechanism of action of tacrolimus in treating $\mathrm{LN}$ is well explained.

However, due to the considerable pharmacokinetic variation among individuals $(74,75)$, the optimal initial dose regimen of tacrolimus in pediatric and adolescent patients with LN has remained to be determined. Population pharmacokinetic models may be useful in predicting individualized therapy by integrating different effects of variables on drug exposure (76), which may determine the initial dosage in different diseases. This includes dose simulation of oxcarbazepine in pediatric patients with epilepsy (77), dose optimization of vancomycin in neonates and young infants (78), dose optimization of azithromycin in pediatric patients with community-acquired pneumonia (79), dose optimization of cyclosporin in pediatric patients with hemophagocytic lymphohistiocytosis (80) and dose optimization of tacrolimus in patients with nephritic syndrome $(81,82)$. Thus, the present study aimed to establish a population pharmacokinetic model of tacrolimus and further optimize the initial dosage regimen of tacrolimus in pediatric and adolescent patients with LN.

In the present study, body weight and co-administration of wuzhi capsule were indicated to influence tacrolimus clearance in pediatric and adolescent patients with LN. A previous similar study demonstrated a non-linear association between drug clearance and body weight in patients (19). In the present study, the rate of tacrolimus clearance in patients who were not administered wuzhi capsule and those who were administered wuzhi capsule with the same body weight was 1:0.71. Wuzhi capsule is a Chinese patent medicine, which contains the primary active ingredients schisandrin, schisantherin A and schisandrol B (83). It has been demonstrated that wuzhi capsule increases the concentration of tacrolimus (84-86) via inhibition of the enzyme cytochrome P450, family 3 (CYP3A) in order to inhibit the metabolization of tacrolimus $(86,87)$. This is able to reduce the dose of tacrolimus required and reduce medical costs, particularly in patients who require to take tacrolimus over a long period of time. In addition, the present study revealed a wide range of hemoglobin levels, which may be due to differences in various physiological or pathological states among the pediatric patients. The specific mechanisms remain to be further explored.

Next, Monte Carlo simulation was used to further predict the optimal dose. This indicated that in patients who weren't administered wuzhi capsule, the initial dosage regimen of $0.15 \mathrm{mg} / \mathrm{kg} /$ day was recommended for a body weight of $10-23 \mathrm{~kg}$ and $0.10 \mathrm{mg} / \mathrm{kg} / \mathrm{day}$ for $23-60 \mathrm{~kg}$; in patients who were co-administered wuzhi capsule, the initial dosage regimen of $0.10 \mathrm{mg} / \mathrm{kg} /$ day was recommended for a body weight of $10-23 \mathrm{~kg}$ and $0.05 \mathrm{mg} / \mathrm{kg} / \mathrm{day}$ for $23-60 \mathrm{~kg}$.

However, there are limitations to the present study. Polymorphisms of CYP3A5 may be associated with tacrolimus required dose; however, the present study was based on real-world data, in which pharmacogenetics were not considered in tacrolimus dosing and therefore, no routine clinical testing was performed with this regard. Therefore, it should be further investigated whether the inclusion of genotyping in this model is able to better explain the variability in the dosage of tacrolimus. In addition, future studies with more patients are required to verify the results of the present study.

In conclusion, to the best of our knowledge, the present study was the first to construct a population pharmacokinetics model of tacrolimus and optimize the initial dosage regimen for tacrolimus treatment in pediatric and adolescent patients with LN.

\section{Acknowledgements}

Not applicable. 


\section{Funding}

This work was supported by the Scientific Research Project of Science and Technology Commission of Shanghai Municipality (grant no. 18DZ1910604/19DZ1910703) and the Shanghai Science and Technology Commission (grant no. 19XD1400900).

\section{Availability of data and materials}

The datasets used and/or analyzed during the current study are available from the corresponding author on reasonable request.

\section{Authors' contributions}

ZL and HX conceived and designed the study. XC and DW collected and analyzed the data. XC wrote the manuscript. All authors read and approved the final manuscript.

\section{Ethics approval and informed consent to participate}

The study was approved by the Research Ethics Committee of the Children's Hospital of Fudan University (Shanghai, China). The present study was a retrospective study and the analysis was approved by the Ethics Committee of the hospital without the requirement for written informed consent.

\section{Patient consent for publication}

Not applicable.

\section{Competing interests}

The authors declare that they have no competing interests.

\section{References}

1. Papadimitraki ED and Isenberg DA: Childhood- and adult-onset lupus: An update of similarities and differences. Expert Rev Clin Immunol 5: 391-403, 2009.

2. Takeuchi T, Tsuzaka K, Abe T, Yoshimoto K, Shiraishi K, Kameda $\mathrm{H}$ and Amano K: T cell abnormalities in systemic lupus erythematosus. Autoimmunity 38: 339-346, 2005.

3. Rahman A and Isenberg DA: Systemic lupus erythematosus. N Engl J Med 358: 929-939, 2008

4. Gurevitz SL, Snyder JA, Wessel EK, Frey J and Williamson BA: Systemic lupus erythematosus: A review of the disease and treatment options. Consult Pharm 28: 110-121, 2013.

5. D'Cruz DP, Khamashta MA and Hughes GR: Systemic lupus erythematosus. Lancet 369: 587-596, 2007.

6. Huang JL, Yeh KW, Yao TC, Huang YL, Chung HT, Ou LS, Lee WI and Chen LC: Pediatric lupus in Asia. Lupus 19: $1414-1418,2010$

7. Tanaka H, Joh K and Imaizumi T: Treatment of pediatric-onset lupus nephritis: A proposal of optimal therapy. Clin Exp Nephrol 21: 755-763, 2017.

8. Takei S, Maeno N, Shigemori M, Imanaka H, Mori H, Nerome Y, Kanekura S, Takezaki T, Hokonohara M, Miyata K and Fujikawa S: Clinical features of Japanese children and adolescents with systemic lupus erythematosus: Results of 1980-1994 survey. Acta Paediatr Jpn 39: 250-256, 1997.

9. Bertsias GK, Tektonidou M, Amoura Z, Aringer M, Bajema I, Berden JH, Boletis J, Cervera R, Dörner T, Doria A, et al: Joint European league against rheumatism and European renal association-European dialysis and transplant association (EULAR/ERA-EDTA) recommendations for the management of adult and paediatric lupus nephritis. Ann Rheum Dis 71: $1771-1782,2012$
10. Zhou T, Lin S, Yang S and Lin W: Efficacy and safety of tacrolimus in induction therapy of patients with lupus nephritis. Drug Des Devel Ther 13: 857-869, 2019.

11. Vadcharavivad S, Praisuwan S, Techawathanawanna N, Treyaprasert W and Avihingsanon Y: Population pharmacokinetics of tacrolimus in Thai kidney transplant patients: Comparison with similar data from other populations. J Clin Pharm Ther 41: 310-328, 2016.

12. Wang D, Chen X, Xu H and Li Z: Population pharmacokinetics and dosing regimen optimization of tacrolimus in Chinese pediatric hematopoietic stem cell transplantation patients. Xenobiotica 50: 178-185, 2020.

13. Wang DD, Lu JM, Li Q and Li ZP: Population pharmacokinetics of tacrolimus in paediatric systemic lupus erythematosus based on real-world study. J Clin Pharm Ther 43: 476-483, 2018.

14. Chen X, Wang D, Xu H and Li Z: Initial dose optimization of tacrolimus for children with systemic lupus erythematosus based on the CYP3A5 polymorphism and coadministration with Wuzhi capsule. J Clin Pharm Ther 45: 309-317, 2020.

15. Mizuno T, Fukuda T, Christians U, Perentesis JP, Fouladi M and Vinks AA: Population pharmacokinetics of temsirolimus and sirolimus in children with recurrent solid tumours: A report from the Children's Oncology Group. Br J Clin Pharmacol 83: 1097-1107, 2017.

16. Yang JW, Liao SS, Zhu LQ, Zhao Y, Zhang Y, Sun XY, Rao W, $\mathrm{Qu} \mathrm{W,} \mathrm{Li} \mathrm{WZ} \mathrm{and} \mathrm{Sun} \mathrm{LY:} \mathrm{Population} \mathrm{pharmacokinetic} \mathrm{analysis}$ of tacrolimus early after Chinese pediatric liver transplantation. Int J Clin Pharmacol Ther 53: 75-83, 2015.

17. Lindbom L, Pihlgren P and Jonsson EN: PsN-Toolkit-a collection of computer intensive statistical methods for non-linear mixed effect modeling using NONMEM. Comput Methods Programs Biomed 79: 241-257, 2005.

18. Jusko WJ, Piekoszewski W, Klintmalm GB, Shaefer MS, Hebert MF, Piergies AA, Lee CC, Schechter P and Mekki QA: Pharmacokinetics of tacrolimus in liver transplant patients. Clin Pharmacol Ther 57: 281-290, 1995.

19. Anderson BJ and Holford NH: Mechanism-based concepts of size and maturity in pharmacokinetics. Annu Rev Pharmacol Toxicol 48: 303-332, 2008.

20. Ho S, Clipstone N, Timmermann L, Northrop J, Graef I, Fiorentino D, Nourse J and Crabtree GR: The mechanism of action of cyclosporin A and FK506. Clin Immunol Immunopathol 80: S40-S45, 1996.

21. Wang DD, Chen X and Li ZP: Tacrolimus ameliorates proteinuria in Chinese pediatric lupus nephritis patients. Int J Clin Exp Med 12: 10931-10937, 2019.

22. Andreu F, Colom H, Grinyo JM, Torras J, Cruzado JM and Lloberas N: Development of a population PK model of tacrolimus for adaptive dosage control in stable kidney transplant patients. Ther Drug Monit 37: 246-255, 2015.

23. Benkali K, Rostaing L, Premaud A, Woillard JB, Saint-Marcoux F, Urien S, Kamar N, Marquet P and Rousseau A: Population pharmacokinetics and Bayesian estimation of tacrolimus exposure in renal transplant recipients on a new once-daily formulation. Clin Pharmacokinet 49: 683-692, 2010.

24. Bergmann TK, Hennig S, Barraclough KA, Isbel NM and Staatz CE: Population pharmacokinetics of tacrolimus in adult kidney transplant patients: Impact of CYP3A5 genotype on starting dose. Ther Drug Monit 36: 62-70, 2014.

25. Han N, Ha S, Yun HY, Kim MG, Min SI, Ha J, Lee JI, Oh JM and Kim IW: Population pharmacokinetic-pharmacogenetic model of tacrolimus in the early period after kidney transplantation. Basic Clin Pharmacol Toxicol 114: 400-406, 2014.

26. Zhao W, Elie V, Roussey G, Brochard K, Niaudet P, Leroy V, Loirat C, Cochat P, Cloarec S, André JL, et al: Population pharmacokinetics and pharmacogenetics of tacrolimus in de novo pediatric kidney transplant recipients. Clin Pharmacol Ther 86: 609-618, 2009.

27. Zuo XC, Ng CM, Barrett JS, Luo AJ, Zhang BK, Deng $\mathrm{CH}$, Xi LY, Cheng K, Ming YZ, Yang GP, et al: Effects of CYP3A4 and CYP3A5 polymorphisms on tacrolimus pharmacokinetics in Chinese adult renal transplant recipients: A population pharmacokinetic analysis. Pharmacogenet Genomics 23: 251-261, 2013.

28. Lu YX, Su QH, Wu KH, Ren YP, Li L, Zhou TY and Lu W: A population pharmacokinetic study of tacrolimus in healthy Chinese volunteers and liver transplant patients. Acta Pharmacol Sin 36: 281-288, 2015. 
29. Musuamba FT, Guy-Viterbo V, Reding R, Verbeeck RK and Wallemacq P: Population pharmacokinetic analysis of tacrolimus early after pediatric liver transplantation. Ther Drug Monit 36: $54-61,2014$

30. Wallin JE, Bergstrand M, Wilczek HE, Nydert PS, Karlsson MO and Staatz CE: Population pharmacokinetics of tacrolimus in pediatric liver transplantation: Early posttransplantation clearance. Ther Drug Monit 33: 663-672, 2011.

31. Zhang XQ, Wang ZW, Fan JW, Li YP, Jiao Z, Gao JW, Peng ZH and Liu GL: The impact of sulfonylureas on tacrolimus apparent clearance revealed by a population pharmacokinetics analysis in Chinese adult liver-transplant patients. Ther Drug Monit 34: 126-133, 2012.

32. Zhu L, Yang J, Zhang Y, Jing Y, Zhang Y and Li G: Effects of CYP3A5 genotypes, ABCB1 C3435T and G2677T/A polymorphism on pharmacokinetics of Tacrolimus in Chinese adult liver transplant patients. Xenobiotica 45: 840-846, 2015.

33. Wang DD, Chen X, Fu M, Zheng QS, Xu H and Li ZP: Model extrapolation to a real-world dataset: Evaluation of tacrolimus population pharmacokinetics and drug interaction in pediatric liver transplantation patients. Xenobiotica 50: 371-379, 2020.

34. Wang DD, Chen X and Li ZP: Wuzhi capsule and haemoglobin influence tacrolimus elimination in paediatric kidney transplantation patients in a population pharmacokinetics analysis: A retrospective study. J Clin Pharm Ther 44: 611-617, 2019.

35. Fay JW, Nash RA, Wingard JR, Przepiorka D, Collins RH, Anasetti C, Devine SM, Pineiro LA, Storb RF, Aro RM, et al: FK 506-based immunosuppression for prevention of graft versus host disease after unrelated donor marrow transplantation. Transplant Proc 27: 1374, 1995.

36. Fay JW,Wingard JR, Antin JH,Collins RH,PiñeiroLA,Blazar BR, Saral R, Bierer BE, Przepiorka D, Fitzsimmons WE, et al: FK506 (Tacrolimus) monotherapy for prevention of graft-versus-host disease after histocompatible sibling allogenic bone marrow transplantation. Blood 87: 3514-3519, 1996.

37. Nash RA, Etzioni R, Storb R, Furlong T, Gooley T, Anasetti C, Appelbaum FR, Doney K, Martin P, Slattery J, et al: Tacrolimus (FK506) alone or in combination with methotrexate or methylprednisolone for the prevention of acute graft-versus-host disease after marrow transplantation from HLA-matched siblings: A single-center study. Blood 85 : 3746-3753, 1995.

38. Nash RA, Piñeiro LA, Storb R, Deeg HJ, Fitzsimmons WE, Furlong T, Hansen JA, Gooley T, Maher RM, Martin P, et al: FK506 in combination with methotrexate for the prevention of graft-versus-host disease after marrow transplantation from matched unrelated donors. Blood 88: 3634-3641, 1996.

39. Przepiorka D, Ippoliti C, Khouri I, Woo M, Mehra R, Le Bherz D, Giralt S, Gajewski J, Fischer H, Fritsche H, et al: Tacrolimus and minidose methotrexate for prevention of acute graft-versus-host disease after matched unrelated donor marrow transplantation. Blood 88: 4383-4389, 1996

40. Uberti JP, Silver SM, Adams PT, Jacobson P, Scalzo A and Ratanatharathorn V: Tacrolimus and methotrexate for the prophylaxis of acute graft-versus-host disease in allogeneic bone marrow transplantation in patients with hematologic malignancies. Bone Marrow Transplant 19: 1233-1238, 1997.

41. Nash RA, Antin JH, Karanes C, Fay JW, Avalos BR, Yeager AM, Przepiorka D, Davies S, Petersen FB, Bartels P, et al: Phase 3 study comparing methotrexate and tacrolimus with methotrexate and cyclosporine for prophylaxis of acute graft-versus-host disease after marrow transplantation from unrelated donors. Blood 96: 2062-2068, 2000.

42. Wang D, Chen X, Xu H and Li Z: Population pharmacokinetics and dosing regimen optimisation of tacrolimus in Chinese pediatric hematopoietic stem cell transplantation patients. Xenobiotica 50: 178-185, 2020.

43. Monchaud C, de Winter BC, Knoop C, Estenne M, Reynaud-Gaubert M, Pison C, Stern M, Kessler R, Guillemain R, Marquet $\mathrm{P}$ and Rousseau A: Population pharmacokinetic modelling and design of a Bayesian estimator for therapeutic drug monitoring of tacrolimus in lung transplantation. Clin Pharmacokinet 51: 175-186, 2012.

44. Han Y, Zhou H, Cai J, Huang J, Zhang J, Shi SJ, Liu YN and Zhang Y: Prediction of tacrolimus dosage in the early period after heart transplantation: A population pharmacokinetic approach. Pharmacogenomics 20: 21-35, 2019.
45. Chandrasekhara PK, Jayachandran NV, Thomas J, Agrawal S and Narsimulu G: Successful treatment of pyoderma gangrenosum associated with juvenile idiopathic arthritis with a combination of topical tacrolimus and oral prednisolone. Clin Rheumatol 28: 489-490, 2009.

46. Shimizu M, Ueno K, Ishikawa S, Tokuhisa Y, Inoue N and Yachie A: Treatment of refractory polyarticular juvenile idiopathic arthritis with tacrolimus. Rheumatology (Oxford) 53: $2120-2122,2014$

47. Tanaka H, Tsugawa K, Suzuki K, Oki ES, Nonaka K, Kimura S and Ito E: Treatment of difficult cases of systemic-onset juvenile idiopathic arthritis with tacrolimus. Eur J Pediatr 166: 1053-1055, 2007.

48. Wang D, Chen X and Li Z: Treatment of patients with systemic-onset juvenile idiopathic arthritis with tacrolimus. Exp Ther Med 17: 2305-2309, 2019.

49. Choudhry S, Bagga A, Hari P, Sharma S, Kalaivani M and Dinda A: Efficacy and safety of tacrolimus versus cyclosporine in children with steroid-resistant nephrotic syndrome: A randomized controlled trial. Am J Kidney Dis 53: 760-769, 2009.

50. Gulati A, Sinha A, Gupta A, Kanitkar M, Sreenivas V, Sharma J, Mantan M, Agarwal I, Dinda AK, Hari P and Bagga A: Treatment with tacrolimus and prednisolone is preferable to intravenous cyclophosphamide as the initial therapy for children with steroid-resistant nephrotic syndrome. Kidney Int 82: 1130-1135, 2012.

51. Gulati S, Prasad N, Sharma RK, Kumar A, Gupta A and Baburaj VP: Tacrolimus: A new therapy for steroid-resistant nephrotic syndrome in children. Nephrol Dial Transplant 23: 910-913, 2008.

52. Loeffler K, Gowrishankar M and Yiu V: Tacrolimus therapy in pediatric patients with treatment-resistant nephrotic syndrome. Pediatr Nephrol 19: 281-287, 2004

53. Roberti I and Vyas S: Long-term outcome of children with steroid-resistant nephrotic syndrome treated with tacrolimus. Pediatr Nephrol 25: 1117-1124, 2010.

54. Yang EM, Lee ST, Choi HJ, Cho HY, Lee JH, Kang HG, Park YS, Cheong HI and Ha IS: Tacrolimus for children with refractory nephrotic syndrome: A one-year prospective, multicenter, and open-label study of Tacrobell(R), a generic formula. World J Pediatr 12: 60-65, 2016.

55. Wang D, Lu J, Li Q and Li Z: Population pharmacokinetics of tacrolimus in pediatric refractory nephrotic syndrome and a summary of other pediatric disease models. Exp Ther Med 17: 4023-4031, 2019

56. Duddridge $M$ and Powell RJ: Treatment of severe and difficult cases of systemic lupus erythematosus with tacrolimus. A report of three cases. Ann Rheum Dis 56: 690-692, 1997.

57. Miyasaka N, Kawai S and Hashimoto H: Efficacy and safety of tacrolimus for lupus nephritis: A placebo-controlled double-blind multicenter study. Mod Rheumatol 19: 606-615, 2009.

58. Watanabe H, Yamanaka R, Sada KE, Zeggar S, Katsuyama E, Katsuyama T, Narazaki MT, Tatebe NT, Sugiyama K, Watanabe KS, et al: The efficacy of add-on tacrolimus for minor flare in patients with systemic lupus erythematosus: A retrospective study. Lupus 25: 54-60, 2016.

59. Yoon KH: Efficacy and cytokine modulating effects of tacrolimus in systemic lupus erythematosus: A review. J Biomed Biotechnol 2010: 686480, 2010

60. Szeto CC, Kwan BC, Lai FM, Tam LS, Li EK, Chow KM, Gang W and Li PK: Tacrolimus for the treatment of systemic lupus erythematosus with pure class $\mathrm{V}$ nephritis. Rheumatology (Oxford) 47: 1678-1681, 2008

61. Kusunoki Y, Tanaka N, Kaneko K, Yamamoto T, Endo H and Kawai S: Tacrolimus therapy for systemic lupus erythematosus without renal involvement: A preliminary retrospective study. Mod Rheumatol 19: 616-621, 2009.

62. Alsuwaida A: Successful management of systemic lupus erythematosus nephritis flare-up during pregnancy with tacrolimus. Mod Rheumatol 21: 73-75, 2011.

63. Li H,Zhang X and Chen J: Successful treatment of steroid-refractory systemic lupus erythematosus-associated protein-losing enteropathy using combination therapy with tacrolimus and steroid. Lupus 20: 1109-1111, 2011.

64. Kaieda S, Kobayashi T, Moroki M, Honda S, Yuge K, Kawano H, Mitsuyama K, Sata M, Ida H, Hoshino T and Fukuda T: Successful treatment of rectal ulcers in a patient with systemic lupus erythematosus using corticosteroids and tacrolimus. Mod Rheumatol 24: 357-360, 2014. 
65. Politt D, Heintz B, Floege J and Mertens PR: Tacrolimus-(FK 506) based immunosuppression in severe systemic lupus erythematosus. Clin Nephrol 62: 49-53, 2004.

66. Zhang Z, Yang C, Zhang L, Yi Q and Hao Z: Efficacy and safety of tacrolimus in myasthenia gravis: A systematic review and meta-analysis. Ann Indian Acad Neurol 20: 341-347, 2017.

67. Wang L, Zhang S, Xi J, Li W, Zhou L, Lu J, Lu J, Zhang T and Zhao C: Efficacy and safety of tacrolimus for myasthenia gravis: A systematic review and meta-analysis. J Neurol 264: 2191-2200, 2017.

68. Komaki Y, Komaki F, Ido A and Sakuraba A: Efficacy and safety of tacrolimus therapy for active ulcerative colitis; A systematic review and meta-analysis. J Crohns Colitis 10: 484-494, 2016.

69. Matsuoka K, Saito E, Fujii T, Takenaka K, Kimura M, Nagahori M, Ohtsuka K and Watanabe M: Tacrolimus for the treatment of ulcerative colitis. Intest Res 13: 219-226, 2015.

70. Hanouneh M, Ritchie MM, Ascha M, Ascha MS, Chedid A, Sanguankeo A, Zein NN and Hanouneh IA: A review of the utility of tacrolimus in the management of adults with autoimmune hepatitis. Scand J Gastroenterol 54: 76-80, 2019.

71. Scott LJ, McKeage K, Keam SJ and Plosker GL: Tacrolimus: A further update of its use in the management of organ transplantation. Drugs 63: 1247-1297, 2003.

72. Naesens M, Kuypers DR and Sarwal M: Calcineurin inhibitor nephrotoxicity. Clin J Am Soc Nephrol 4: 481-508, 2009.

73. Entani C, Izumino K, Iida H, Fujita M, Asaka M, Takata M and Sasayama S: Effect of a novel immunosuppressant, FK506, on spontaneous lupus nephritis in $\mathrm{MRL} / \mathrm{MpJ}-\mathrm{lpr} / \mathrm{lpr}$ mice. Nephron 64: 471-475, 1993.

74. Jusko WJ, Thomson AW, Fung J, McMaster P, Wong SH Zylber-Katz E, Christians U, Winkler M, Fitzsimmons WE, Lieberman R, et al: Consensus document: Therapeutic monitoring of tacrolimus (FK-506). Ther Drug Monit 17: 606-614, 1995.

75. Venkataramanan R, Swaminathan A, Prasad T, Jain A, Zuckerman S, Warty V, McMichael J, Lever J, Burckart G and Starzl T: Clinical pharmacokinetics of tacrolimus. Clin Pharmacokinet 29: 404-430, 1995.

76. Zheng QS and Li LJ: Pharmacometrics: A quantitative tool of pharmacological research. Acta Pharmacol Sin 33: 1337-1338, 2012.

77. Chen CY, Zhou Y, Cui YM, Yang T, Zhao X and Wu Y: Population pharmacokinetics and dose simulation of oxcarbazepine in Chinese paediatric patients with epilepsy. J Clin Pharm Ther 44: 300-311, 2019.

78. Chen Y, Wu D, Dong M, Zhu Y, Lu J, Li X, Chen C and Li Z: Population pharmacokinetics of vancomycin and AUC-guided dosing in Chinese neonates and young infants. Eur J Clin Pharmacol 74: 921-930, 2018.
79. Zheng Y, Liu SP, Xu BP, Shi ZR, Wang K, Yang JB, Huang X, Tang BH, Chen XK, Shi HY, et al: Population pharmacokinetics and dosing optimization of azithromycin in children with community-acquired pneumonia. Antimicrob Agents Chemother 62: e00686-18, 2018.

80. Wang DD, Ye QF, Chen X, Xu H and Li ZP: Population pharmacokinetics and initial dosing regimen optimization of cyclosporin in pediatric hemophagocytic lymphohistiocytosis patients. Xenobiotica 50: 435-441, 2020

81. Lu T, Zhu X, Xu S, Zhao M, Huang X, Wang Z and Zhao L: Dosage optimization based on population pharmacokinetic analysis of tacrolimus in chinese patients with nephrotic syndrome. Pharm Res 36: 45, 2019

82. Wang X, Han Y, Chen C, Ma L, Xiao H, Zhou Y, Cui Y, Wang F, Su B, Yao Y and Ding J: Population pharmacokinetics and dosage optimization of tacrolimus in pediatric patients with nephrotic syndrome. Int J Clin Pharmacol Ther 57: 125-134, 2019.

83. Wei H, Tao X, Di P, Yang Y, Li J, Qian X, Feng J and Chen W: Effects of traditional chinese medicine Wuzhi capsule on pharmacokinetics of tacrolimus in rats. Drug Metab Dispos 41: 1398-1403, 2013.

84. Xin HW, Li Q, Wu XC, He Y, Yu AR, Xiong L and Xiong Y: Effects of Schisandra sphenanthera extract on the blood concentration of tacrolimus in renal transplant recipients. Eur J Clin Pharmacol 67: 1309-1311, 2011.

85. Xin HW, Wu XC, Li Q, Yu AR, Zhu M, Shen Y, Su D and Xiong L: Effects of Schisandra sphenanthera extract on the pharmacokinetics of tacrolimus in healthy volunteers. Br J Clin Pharmacol 64: 469-475, 2007.

86. Qin XL, Bi HC, Wang CX, Li JL, Wang XD, Liu LS, Chen X and Huang M: Study of the effect of Wuzhi tablet (Schisandra sphenanthera extract) on tacrolimus tissue distribution in rat by liquid chromatography tandem mass spectrometry method. Biomed Chromatogr 24: 399-405, 2010.

87. Qin XL, Bi HC, Wang XD, Li JL, Wang Y, Xue XP, Chen X, Wang CX, Xu le J, Wang YT and Huang M: Mechanistic understanding of the different effects of Wuzhi Tablet (Schisandra sphenanthera extract) on the absorption and first-pass intestinal and hepatic metabolism of Tacrolimus (FK506). Int J Pharm 389: 114-121, 2010.

This work is licensed under a Creative Commons Attribution-NonCommercial-NoDerivatives 4.0 International (CC BY-NC-ND 4.0) License. 